\title{
Uji Sediaan Lotion Nanopartikel Ekstrak Terong Belanda Sebagai Antioksidan
}

\author{
Wulan Agustin Ningrum 1*, Wirasti ${ }^{2}$, Yulian Wahyu Permadi ${ }^{3}$, Fida Faiqatul Himmah ${ }^{4}$, \\ Farahdina Ulfa ${ }^{5}$ \\ 1,2,3,4,5 Fakultas Ilmu Kesehatan Universitas Muhammadiyah Pekajangan Pekalongan, email: \\ wulan1414@yahoo.co.id
}

\begin{abstract}
Abstrak. Nanopartikel adalah suatu teknologi formulasi suatu partikel yang terdispersi pada ukuran nanometer atau skala per seribu mikron. Tujuan penelitian ini adalah membuat sediaan lotion dari nanopartikel ekstrak terong belanda sebagai antioksidan. Teknologi nanopartikel ekstrak terong belanda mempunyai efek yang sangat baik sebagai antioksidan, sehingga dimungkinkan dibuat sediaan sebagai bahan kosmetik Penelitian ini menguji nanopertikel ekstrak terong belanda sebagai antioksidan sediaan lotion. Metode ekstraksi yang digunakan dalam penelitian ini adalah maserasi menggunakan pelarut metanol. Pembuatan teknologi nanopartikel ekstrak terong belanda menggunakan metode nanopertikel berbasis biopolimer. Nanopartikel ekstrak terong belanda diformulasi menjadi sediaan lotion. Uji aktivitas antioksidan dilakukan dengan metode penangkap radikal bebas DPPH. Parameter aktivitas antioksidan yaitu IC50 (Inhibititon Concentration), sedangkan uji sediaan lotion terdiri dari pH, viskositas, stabilitas, organoleptis (warna, aroma, bentuk). Hasil dari penelitian menunjukkan Lotion ekstrak terong belanda yang dihasilkan memenuhi syarat evaluasi fisik sediaan. Nilai IC50 lotion nanopartikel ekstrak terong belanda adalah $62 \mu \mathrm{g} / \mathrm{mL}$. Ukuran partikel dari ekstrak nanopartikel adalah 182,4 $\mu \mathrm{m}$. Lotion nanopartikel ekstrak terong belanda mempunyai kestabilan yang baik. Perlu dilakukan pembuatan bentuk sediaan yang lain dengan tujuan sebagai kosmetika.
\end{abstract}

Kata kunci : Ekstrak terong belanda, nanopartikel, lotion, IC50

\section{Tamarillo Extract Nanoparticle Lotion Preparation Test As Antioxidant}

\begin{abstract}
Nanoparticles are a technology for the formulation of particles that are dispersed at the nanometer size or scale per thousand microns. The purpose of this study was to make lotion preparations from the nanoparticles of tamarillo extract as an antioxidant. The nanoparticle technology of tamarillo extract has a very good effect as an antioxidant, so it is possible to make a cosmetic ingredient. This study tested the nanoparticle extract of tamarillo as an antioxidant for lotion preparations. The extraction method used in this research is maceration using methanol as a solvent. The manufacture of tamarillo extract nanoparticle technology used a biopolymer-based nanoperticle method. The nanoparticles of tamarillo extract were formulated into lotions. The antioxidant activity test was carried out using the DPPH free radical scavenger method. The parameter of antioxidant activity is IC50 (Inhibititon Concentration), while the lotion preparation test consists of $\mathrm{pH}$, viscosity, stability, organoleptic (color, aroma, shape). The results showed that the tamarillo extract lotion produced met the requirements for the physical evaluation of the preparation. The IC50 value of tamarillo extract nanoparticle lotion was $62 \mu \mathrm{g} / \mathrm{mL}$. The particle size of the nanoparticle extract was 182.4 $\mu \mathrm{m}$. Tamarillo extract nanoparticle lotion has good stability. It is necessary to make other dosage forms for the purpose of cosmetics.
\end{abstract}

Keywords: Tamarillo extract, nanoparticle, lotion, IC50

\section{Pendahuluan}

di Indonesia terong belanda mungkin belum banyak dikenal oleh masyarakat, padahal buah ini merupakan komoditi dalam negri yang memiliki potensi baik untuk dikembangkan. Oleh karena itu, diperlukan penelitian untuk memanfaatkan terong belanda sehingga mudah didistribusikan dan dipromosikan. Terong belanda lebih banyak dikonsumsi sebagai buah, baik dimakai segar, dibuat sirup, atau jus (Wahyuni et al., 2013).

Kandungan kimia terong belanda adalah senyawa fenolik dan flavonoid (Susanti et al., 2015). Ekstrak etanol terong belanda memiliki aktivitas antioksidan terbesar dibandingkan tomat cherry, tomat cherry merah dan buah tomat.

Suatu tanaman yang mengandung senyawa fenolik, kemungkinan juga berfungsi sebagai 
antioksidan karena gugus fenoliknya mengangkap radikal bebas. Semakin besar kadar fenolik total suatu simplisia, maka semakin besar daya aktivitas penangkap radikal bebas (daya antioksidannya). Alasan lain yaitu sumber antioksidan alami didominasi oleh tumbuhan dan umumnya mengandung senyawa fenolik yang tersebar di seluruh bagian tumbuhan.

Kelebihan nanopartikel adalah kemampuan untuk menembus ruang-ruang antar sel yang hanya dapat ditembus oleh ukuran partikel koloidal (Abdassah, 2009), kemampuan untuk menembus dinding sel yang lebih tinggi, baik melalui difusi maupun opsonifikasi, dan fleksibilitasnya untuk dikombinasi dengan berbagai teknologi lain sehingga membuka potensi yang luas untuk dikembangkan pada berbagai keperluan dan target (Martien et al., 2012).

Penelitian ini bertujuan menformulasi nanopartikel ekstrak terong belanda menjadi sediaan kosmetik lotion. Pembuatan sediaan kosmetik lotion untuk maksud sebagai antioksidan pada kulit.

\section{Metode}

Penelitian ini dilakukan pada bulan Mei sampai Nopember 2019 di laboratorium fitokimia, farmasetika, kimia Program Studi Sarjana Farmasi Universitas Muhammadiyah Pekajangan Pekalongan Bahan yang digunakan pada penelitian ini adalah terong belanda yang diperoleh dari Kecamatan Kajen Kabupaten Pekalongan, etanol $96 \%$, kitosan, NaTPP (Natrium tipolifosfat), asam glasial 1\%, NaCMC, PGA, gliserol, propilenglikol, sirup simplek, sorbitol, asam benzoat, oleum citrus, aquades.

Alat yang digunakan dalam praktikum ini adalah blender, oven, ayakan mesh 40, toples kaca, sendok, evoporator, magnetic stirer, sentrifuge, gelas beker, timbangan analitik, kertas saring, gelas arloji, Particle Size Analyzer (PSA), Scanning Electron Microscopy (SEM), mortir, gelas ukur, pH meter, viskometer ostward, piknometer, tabung reaksi, mikroskop cahaya.

\section{Pembuatan Nanopartikel Ekstrak Terong Belanda}

Sejumlah 1 gram ekstrak dilarutkan dalam 35 ml etanol pa di campurkan dengan $15 \mathrm{ml}$ aquades dalam beker glass $2000 \mathrm{ml}$, kemudian ditambahkan $100 \mathrm{ml}$ larutan kitosan dalam larutan asam asetat glasial 1\%. Kemudian tambahkan NaTPP $350 \mathrm{ml}$ secara bertahap kedalam campuran tersebut, sambil dilakukan pengadukan dengan magnetic stirrer pada kecepatan yang stabil selama 2 jam (Kurniasari and Atun, 2017). Setelah semua bahan tercampur koloid nanopartikel kitosan NaTPP ekstrak terong belanda dipisahkan dengan cara sentrifugasi padatan yang diperoleh kemudian dimasukan dalam frezzer $\pm 4^{\circ} \mathrm{C}$ selama \pm 2 hari. Penyimpanan dipindahkan dalam lemari es \pm 3 derajat celcius sampai kering (Kurniasari and Atun, 2017), Yang selanjutnya dikeringkan dengan cara pengeringan semprot (spray dying) sehingga didapatkan serbuk kering nanopartikel ekstrak etanol.

Karakterisasi nanopartikel ekstrak etanol terong belanda dikarakterisasi menggunakan Particle Size Analyzer dan zeta sizer (PSA) dan Scaning Electron Microscop (SEM) untuk mengetahui ukuran partikel dan nilai zeta potensial dari nanopartikel ekstrak terong belanda (Dewandari et al., 2013).

\section{Penyiapan dan Pembuatan Sediaan Nanopartikel} Lotion

Tabel 1. Formula lotion dari nanopartikel ekstrak terong belanda

\begin{tabular}{|c|c|c|c|c|}
\hline Bahan & Formula I & $\begin{array}{l}\text { Formula } \\
\text { II }\end{array}$ & $\begin{array}{l}\text { Formula } \\
\text { III }\end{array}$ & Kegunaan \\
\hline Ekstrak & 5 & 5 & 5 & Zat aktif \\
\hline Cera Alba & $2 \%$ & $2 \%$ & $2 \%$ & $\begin{array}{l}\text { Stabilitas } \\
\text { emulsi }\end{array}$ \\
\hline $\begin{array}{l}\text { Asam } \\
\text { stearat }\end{array}$ & $5 \%$ & $5 \%$ & $5 \%$ & $\begin{array}{l}\text { Peningkat } \\
\text { viskositas }\end{array}$ \\
\hline $\mathrm{NaOH}$ & $0,20 \%$ & $0,20 \%$ & $0,20 \%$ & Penetral \\
\hline Carbomer & $0,50 \%$ & $0,50 \%$ & $0,50 \%$ & $\begin{array}{l}\text { Peningkat } \\
\text { viskositas }\end{array}$ \\
\hline $\begin{array}{l}\text { Alfa } \\
\text { Tokoferol }\end{array}$ & $0,01 \%$ & $0,01 \%$ & $0,01 \%$ & Antioksidan \\
\hline Tween 80 & $8,90 \%$ & $8,90 \%$ & $8,90 \%$ & Emulgator \\
\hline Span & $1,10 \%$ & $1,10 \%$ & $1,10 \%$ & Emulgator \\
\hline \multicolumn{5}{|l|}{$\begin{array}{l}\text { Oleum } \\
\text { Rosae }\end{array}$} \\
\hline $\begin{array}{l}\text { Metil } \\
\text { Paraben }\end{array}$ & $0,18 \%$ & $0,18 \%$ & $0,18 \%$ & Pengawet \\
\hline $\begin{array}{l}\text { Propil } \\
\text { Paraben }\end{array}$ & $0,02 \%$ & $0,02 \%$ & $0,02 \%$ & Pengawet \\
\hline Aquades Ad & $100 \%$ & $100 \%$ & $100 \%$ & Pembawa \\
\hline
\end{tabular}

Bahan-bahan fase minyak (Cera alba, asam stearat, Span 80, propil paraben) dimasukkan kedalam beker glas, dipanaskan dan dilebur pada suhu $75^{\circ} \mathrm{C}$ diatas Hot plate dan fase air (tween 80 dan metil paraben) dimasukkan dalam beker glas kemudian panaskan pada suhu yang sama. Kemudisn fase minyak pelan-pelan masukkan ke fase air sambil terus-menerus 
diaduk dengan pengaduk elektrik secara berselang ( pengadukaan 2 menit, istirahat 20 detik). Selanjutnya, dimsukkan nanopartikel ektrak terong belanda dan carbomer yang sudah ditambahkan dengan $\mathrm{NaOH}$ lalu diaduk sampai homogen. Terakhir masukkan pengharum, diaduk sehingga berbentuk lotion yang homogen.

\section{Pengujian Sediaan}

Uji Organoleptis

Mengamati bentuk, warna, dan aroma formula sediaan.

Uji Homogenitas

Mengambil sedikit bentuk sediaan formula, Kemudian diletakkan sedikit sediaan

diantara kedua kaca objek. Diamati susunan partikel-partikel kasar atau ketidakhomogenan. Uji pH

Pengujian pH dilakukan dengan menyiapkan masing-masing sampel sediaan. Elektroda dicelupkan ke dalamsediaan tersebut sampai $\mathrm{pH}$ meter menunjukkan pembacaan yang tetap. Dicatat hasil pemeriksaan.

Pengujian Daya Sebar

Pengujian daya sebar sediaan dengan mengambil 0,5 gram dan diletkkan di tengah kaca arloji. Ambil kaca bulat lain dan diletakkan diatas sediaan dan didiamkan selama 1 menit, selanjutnya diameter penyebarannya di catat.

Uji Viskositas

Pengujian viskositas menggunakan alat Viscosimeter Rionseri VT 04 rotor no2. Rotor ditempatkan di tengah-tengah Mangkok yang berisi sediaan. Amati jarumpenunjuk visksitas. Setelah stabil dibaca pada skala yang terdapat pada viscosimeter.

Cycling Test

Cycling test merupakan pengujian yang dipercepat dengan menyimpan sampel pada suhu $24^{\circ} \mathrm{C}$ selama 24 jam, kemudian dipindahkan kedalam oven yang bersuhu $40^{\circ} \mathrm{C}$ selama 24 jam. Perlakuan ini adalah 1 siklus. Perlakuan diulangi sebanyak 6 siklus, pengamatan dilakukan dengan parameter organoleptik, homogenitas, $\mathrm{pH}$, daya sebar, dan viskositas.

\section{Hasil Penelitian}

a. Uji Organoleptik sebelum dan sesudah kondisi yang dipaksakan

Hasil uji organoleptik yang dilakukan adalah warna, aroma dan bentuk dari sediaan lotion ekstrak terong belanda. Hasil dari uji organoleptik ditunjukkan pada tabel 2 .

Tabel 2. Hasil Uji Organoleptis

\begin{tabular}{|c|c|c|c|c|c|c|}
\hline & \multicolumn{6}{|c|}{ Formula I } \\
\hline & \multicolumn{3}{|c|}{ Nano } & \multicolumn{3}{|c|}{ Ekstrak } \\
\hline & $\begin{array}{c}\text { Mg ke } \\
1 \\
\end{array}$ & $\begin{array}{c}\text { Mg ke } \\
2 \\
\end{array}$ & $\begin{array}{c}\text { Mg ke } \\
3 \\
\end{array}$ & $\begin{array}{c}\text { Mg ke } \\
1 \\
\end{array}$ & $\begin{array}{c}\text { Mg ke } \\
2 \\
\end{array}$ & $\begin{array}{c}\text { Mg ke } \\
3 \\
\end{array}$ \\
\hline Aroma & $\begin{array}{c}\text { Khas } \\
\text { sepert } \\
\text { i teh }\end{array}$ & $\begin{array}{c}\text { Khas } \\
\text { sepert } \\
\text { i teh }\end{array}$ & $\begin{array}{c}\text { Khas } \\
\text { sepert } \\
\text { i teh }\end{array}$ & $\begin{array}{c}\text { Khas } \\
\text { sepert } \\
\text { i teh }\end{array}$ & $\begin{array}{c}\text { Khas } \\
\text { sepert } \\
\text { i teh }\end{array}$ & $\begin{array}{c}\text { Khas } \\
\text { sepert } \\
\text { i teh }\end{array}$ \\
\hline Warna & $\begin{array}{c}\text { Cokla } \\
\text { t tua } \\
(+)\end{array}$ & $\begin{array}{c}\text { Cokla } \\
\text { t tua } \\
(+)\end{array}$ & $\begin{array}{c}\text { Cokla } \\
\text { t tua } \\
(+)\end{array}$ & $\begin{array}{c}\text { Cokla } \\
\text { t tua } \\
(+)\end{array}$ & $\begin{array}{c}\text { Cokla } \\
\text { t tua } \\
(+)\end{array}$ & $\begin{array}{c}\text { Cokla } \\
\text { t tua } \\
(+)\end{array}$ \\
\hline \multirow[t]{4}{*}{ Bentuk } & $\begin{array}{c}\text { Gel } \\
\text { Semi } \\
\text { Solid } \\
(+) \\
\end{array}$ & $\begin{array}{c}\text { Gel } \\
\text { Semi } \\
\text { Solid } \\
(+) \\
\end{array}$ & $\begin{array}{c}\text { Gel } \\
\text { Semi } \\
\text { Solid } \\
(+) \\
\end{array}$ & $\begin{array}{c}\text { Gel } \\
\text { Semi } \\
\text { Solid } \\
(+) \\
\end{array}$ & $\begin{array}{c}\text { Gel } \\
\text { Semi } \\
\text { Solid } \\
(+) \\
\end{array}$ & $\begin{array}{c}\text { Gel } \\
\text { Semi } \\
\text { Solid } \\
(+) \\
\end{array}$ \\
\hline & \multicolumn{6}{|c|}{ Formula II } \\
\hline & \multicolumn{3}{|c|}{ Nano } & \multicolumn{3}{|c|}{ Ekstrak } \\
\hline & $\begin{array}{c}\text { Mg ke } \\
1\end{array}$ & $\begin{array}{c}\text { Mg ke } \\
2\end{array}$ & $\begin{array}{c}\text { Mg ke } \\
3\end{array}$ & $\begin{array}{c}\text { Mg ke } \\
1\end{array}$ & $\begin{array}{c}\text { Mg ke } \\
2\end{array}$ & $\begin{array}{c}\text { Mg ke } \\
3\end{array}$ \\
\hline Aroma & $\begin{array}{c}\text { Khas } \\
\text { sepert } \\
\text { i teh }\end{array}$ & $\begin{array}{c}\text { Khas } \\
\text { sepert } \\
\text { i teh }\end{array}$ & $\begin{array}{c}\text { Khas } \\
\text { sepert } \\
\text { i teh }\end{array}$ & $\begin{array}{c}\text { Khas } \\
\text { sepert } \\
\text { i teh }\end{array}$ & $\begin{array}{c}\text { Khas } \\
\text { sepert } \\
\text { i teh }\end{array}$ & $\begin{array}{c}\text { Khas } \\
\text { sepert } \\
\text { i the }\end{array}$ \\
\hline Warna & $\begin{array}{l}\text { Cokla } \\
\text { t tua } \\
(++)\end{array}$ & $\begin{array}{c}\text { Cokla } \\
\text { t tua } \\
(++)\end{array}$ & $\begin{array}{l}\text { Cokla } \\
\text { t tua } \\
(++)\end{array}$ & $\begin{array}{c}\text { Cokla } \\
\text { t tua } \\
(++)\end{array}$ & $\begin{array}{l}\text { Cokla } \\
\text { t tua } \\
(++)\end{array}$ & $\begin{array}{l}\text { Cokla } \\
\text { t tua } \\
(++)\end{array}$ \\
\hline \multirow[t]{4}{*}{ Bentuk } & $\begin{array}{c}\text { Gel } \\
\text { Semi } \\
\text { Solid } \\
(++)\end{array}$ & $\begin{array}{c}\text { Gel } \\
\text { Semi } \\
\text { Solid } \\
(++)\end{array}$ & $\begin{array}{c}\text { Gel } \\
\text { Semi } \\
\text { Solid } \\
(++)\end{array}$ & $\begin{array}{c}\text { Gel } \\
\text { Semi } \\
\text { Solid } \\
(++)\end{array}$ & $\begin{array}{c}\text { Gel } \\
\text { Semi } \\
\text { Solid } \\
(++)\end{array}$ & $\begin{array}{c}\text { Gel } \\
\text { Semi } \\
\text { Solid } \\
(++)\end{array}$ \\
\hline & \multicolumn{6}{|c|}{ Formula III } \\
\hline & \multicolumn{3}{|c|}{ Nano } & \multicolumn{3}{|c|}{ Ekstrak } \\
\hline & $\begin{array}{c}\text { Mg ke } \\
1 \\
\end{array}$ & $\begin{array}{c}\text { Mg ke } \\
2 \\
\end{array}$ & $\begin{array}{c}\text { Mg ke } \\
3 \\
\end{array}$ & $\begin{array}{c}\text { Mg ke } \\
1\end{array}$ & $\begin{array}{c}\text { Mg ke } \\
2\end{array}$ & $\begin{array}{c}\text { Mg ke } \\
3 \\
\end{array}$ \\
\hline Aroma & $\begin{array}{c}\text { Khas } \\
\text { sepert } \\
\text { i teh }\end{array}$ & $\begin{array}{c}\text { Khas } \\
\text { sepert } \\
\text { i teh }\end{array}$ & $\begin{array}{c}\text { Khas } \\
\text { sepert } \\
\text { i teh }\end{array}$ & $\begin{array}{c}\text { Khas } \\
\text { sepert } \\
\text { i teh }\end{array}$ & $\begin{array}{c}\text { Khas } \\
\text { sepert } \\
\text { i teh }\end{array}$ & $\begin{array}{c}\text { Khas } \\
\text { sepert } \\
\text { i teh }\end{array}$ \\
\hline Warna & $\begin{array}{c}\text { Cokla } \\
\text { t tua } \\
(+++)\end{array}$ & $\begin{array}{c}\text { Cokla } \\
\text { t tua } \\
(+++)\end{array}$ & $\begin{array}{c}\text { Cokla } \\
\text { t tua } \\
(+++)\end{array}$ & $\begin{array}{c}\text { Cokla } \\
\text { t tua } \\
(+++)\end{array}$ & $\begin{array}{c}\text { Cokla } \\
\text { t tua } \\
(+++)\end{array}$ & $\begin{array}{c}\text { Cokla } \\
\text { t tua } \\
(+++)\end{array}$ \\
\hline Bentuk & $\begin{array}{c}\text { Gel } \\
\text { Semi } \\
\text { Solid } \\
(+++)\end{array}$ & $\begin{array}{c}\text { Gel } \\
\text { Semi } \\
\text { Solid } \\
(+++)\end{array}$ & $\begin{array}{c}\text { Gel } \\
\text { Semi } \\
\text { Solid } \\
(+++)\end{array}$ & $\begin{array}{c}\text { Gel } \\
\text { Semi } \\
\text { Solid } \\
(+++)\end{array}$ & $\begin{array}{c}\text { Gel } \\
\text { Semi } \\
\text { Solid } \\
(+++)\end{array}$ & $\begin{array}{c}\text { Gel } \\
\text { Semi } \\
\text { Solid } \\
(+++)\end{array}$ \\
\hline
\end{tabular}

b. Uji Homogenitas Sebelum dan sesudah kondisi dipaksakan

Pengujian homogenitas bertujuan untuk mengetahui homogenitas suatu sediaan ketika saat dibuat dan untuk mengetahui perubahan 
homogenitas yang mungkin terjadi selama penyimpanan. Hasil uji homogenitas ditunjukkan dalam tabel 3 .

Tabel 3. Hasil Uji Homogenitas Sebelum dan Sesudah Kondisi Dipaksakan

\begin{tabular}{cccc}
\hline \multirow{4}{*}{ Formula } & \multicolumn{3}{c}{ MingguKe- } \\
& 1 & 2 & 3 \\
\hline I & Homogen & Homogen & Homogen \\
II & Homogen & Homogen & Homogen \\
III & Homogen & Homogen & Homogen \\
\hline
\end{tabular}

c. Uji Daya Sebar

Pengujian daya sebar dilakukan untuk mengetahui kemampuan penyebaran sediaan krim saat diaplikasikan ke kulit. Kemampuan penyebaran basis yang baik akan memberikan kemudahan pengaplikasian ke permukaan kulit. Kisaran daya sebar yaitu 5 - $7 \mathrm{~cm}$. Hasil uji daya sebar lotion ekstrak ditunjukakan pada tabel 4.

Tabel 4. Hasil Uji Daya Sebar

\begin{tabular}{|c|c|c|c|}
\hline \multicolumn{4}{|c|}{ Diameter Daya Sebar (cm) Fomula I } \\
\hline Beban (gram) & $\begin{array}{c}\text { Minggu } \\
\text { ke-1 }\end{array}$ & $\begin{array}{c}\text { Minggu } \\
\text { ke-2 }\end{array}$ & $\begin{array}{c}\text { Minggu } \\
\text { ke-3 }\end{array}$ \\
\hline Tanpa Beban & 4 & 4 & 4 \\
\hline 50 & 4,5 & 4,8 & 5 \\
\hline 100 & 5 & 5,5 & 5,1 \\
\hline 150 & 6 & 5,5 & 5,5 \\
\hline 200 & 6,1 & 5,8 & 5,4 \\
\hline 250 & 6,5 & 6 & 5,5 \\
\hline \multicolumn{4}{|c|}{ Diameter Daya Sebar $(\mathrm{cm})$ Formula II } \\
\hline $\begin{array}{l}\text { Beban } \\
\text { (gram) }\end{array}$ & $\begin{array}{c}\text { Minggu } \\
\text { ke-1 } \\
\end{array}$ & $\begin{array}{c}\text { Minggu } \\
\text { ke-2 } \\
\end{array}$ & $\begin{array}{c}\text { Minggu } \\
\text { ke-3 } \\
\end{array}$ \\
\hline $\begin{array}{l}\text { Tanpa } \\
\text { Beban }\end{array}$ & 3,5 & 4 & 4 \\
\hline 50 & 4 & 4,5 & 5 \\
\hline 100 & 4,6 & 5 & 5,2 \\
\hline 150 & 5 & 5,5 & 5,5 \\
\hline 200 & 5,5 & 6 & 5,6 \\
\hline 250 & 5,5 & 6 & 6 \\
\hline
\end{tabular}

\begin{tabular}{cccc}
\hline \multicolumn{4}{c}{ Diameter Daya sebar $(\mathrm{cm})$ Formula III } \\
\hline $\begin{array}{c}\text { Beban } \\
\text { gram })\end{array}$ & $\begin{array}{c}\text { Minggu } \\
\text { ke-1 }\end{array}$ & $\begin{array}{c}\text { Minggu } \\
\text { ke-2 }\end{array}$ & $\begin{array}{c}\text { Minggu } \\
\text { ke-3 }\end{array}$ \\
\hline $\begin{array}{c}\text { Tanpa } \\
\text { Beban }\end{array}$ & 2,7 & 4 & 4 \\
50 & 3,2 & 4,5 & \\
100 & 3,3 & 5,2 & 5,1 \\
150 & 3,2 & 5,5 & 5,8
\end{tabular}

\begin{tabular}{cccc}
200 & 3,5 & 5,6 & 6 \\
250 & 3,5 & 6,6 & 6,3 \\
\hline
\end{tabular}

\section{d. Uji pH}

Pemeriksaan pH merupakan parameter fisikokimia yang harus dilakukan untuk sediaan topikal karena $\mathrm{pH}$ berkaitan dengan efektivitas zat aktif, stabilitas zat aktif dan sediaan, serta kenyamanan di kulit sewaktu digunakan. pH yang terlalu asam dapat mengakibatkan iritasi sedangkan pH yang terlalu basa dapat menyebabkan kulit bersisik. Hasil uji pH kondisi dipaksakan dari minggi ke 1 sampai minggu ke 3 ditunjukkan pada tabel 5 .

\begin{tabular}{ccccccc}
\hline & \multicolumn{6}{c}{ Minggu ke } \\
\cline { 2 - 7 } Formula & \multicolumn{2}{c}{1} & \multicolumn{2}{c}{2} & \multicolumn{2}{c}{3} \\
\cline { 2 - 7 } & Ekstrak & Nano & Ekstrak & Nano & Ekstrak & Nano \\
\cline { 2 - 7 } I & 6 & 6,5 & 5,5 & 6 & 4,8 & 5,8 \\
II & 5,2 & 6,3 & 5,5 & 6,5 & 5,4 & 6 \\
III & 5,2 & 6,5 & 5,5 & 6,5 & 5,2 & 6,2 \\
\hline
\end{tabular}

Tabel 5. Hasil Uji pH pada kondisi yang dipaksakan

\section{e. Uji Viskositas}

Pengujian viskositas menggunakan alat Viscosimeter Rionseri VT 04 rotor no2. Rotor ditempatkan di tengah-tengah Mangkok yang berisi sediaan. Amati jarum penunjuk viskositas. Setelah stabil dibaca pada skala yang terdapat pada viscosimeter. Hasil uji viskosimeter ditunjukkan pada tabel 6 .

Tabel 6. Hasil Uji Viskositas Pada Kondisi yang dipaksakan

\begin{tabular}{cccc}
\hline \multirow{2}{*}{ Formula } & \multicolumn{3}{c}{ MingguKe- } \\
& 1 & 2 & 3 \\
\hline I & 3928 & 3929 & 3932 \\
II & 3928 & 3929 & 3932 \\
III & 3928 & 3929 & 3932 \\
\hline
\end{tabular}

f. Hasil Uji Antioksidan

Analisis aktivitas antioksidan dilakukan pada kedua formulasi lotion ekstrak terong belanda terong belanda dengan metode DPPH free radical scavenging berkaitan dengan fungsinya sebagai sumber antioksidan. Hasil Uji Antioksidan dan Daya antioksidan ditampilkan pada tabel 7 dan gambar 1 . 
Tabel 7. Hasil Uji Antioksidan Lotion

\begin{tabular}{cc}
\hline Sediaan & IC50 $(\mu \mathrm{g} / \mathbf{m L})$ \\
\hline Lotion ekstrak & 94 \\
Lotion nano & 62 \\
\hline
\end{tabular}

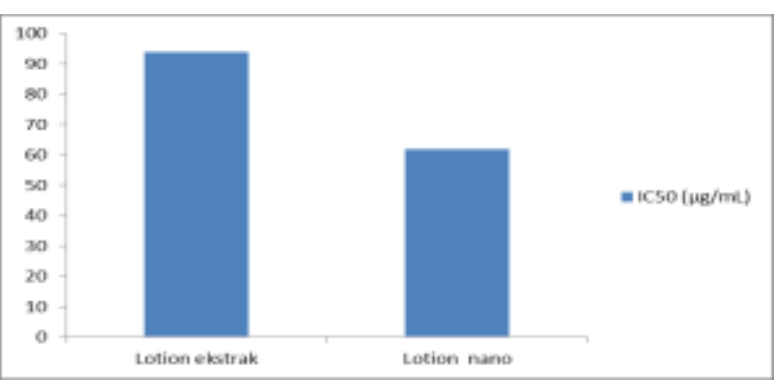

Gambar 1. Daya antioksidan Lotion ekstrak dan lotion nanopartikel terong belanda

\section{Pembahasan}

Hasil Uji Organoleptis sediaan lotion nanopartikel ekstrak terong belanda menunjukkan bau yang dihasilkan dari sediaan lotion ekstrak dan lotion nanopartikel ekstrak terong belanda. Hasil yang didapat antara keduanya sama yaitu khas. Aroma ini disebabkan karena bau simplisia dari terong belanda. Baik lotion ekstrak maupun lotion nanopartikel menunjukkan bau khas.

Warna dari kedua sediaan tidak berbeda. Warna yang dihasilkan adalah coklat tua. Warna ini adalah warna asli dari buah terung belanda yang berwarna coklat kemerahan setelah di ekstrak dihasilkan warna coklat. Warna yang dihasilkan dari minggu ke 1 sampai minggu ke 3 semakin tua, hal ini kemungkinan ada sedikit teroksidasi dari ekstrak atau bentuk nanopartikelnya yang disebabkan karena oksigen atau cahaya pada perlakuan.

Bentuk sediaan lotion pada umumnya adalah semi solid. Hasil dari preparasi sediaan lotion ini ekstrak maupun lotion nanopartikel adalah semisolid. Bentuk sediaan minggu ke 1 sampai minggu ke 3 tidak terjadi perubahan.

Hasil Uji Homogenitas ditunjukkan dengan tidak adanya partikel-partikel yang kasar dan memisah pada sediaan. Sediaan dikatakan homogen bila terdapat persamaan warna yang merata dan tidak adanya partikel atau bahan kasar yang dapat diraba. Persyaratan homogenitas gel dimaksudkan agar bahan aktif dalam gel terdistribusi merata. Kedua sediaan lotion ekstrak terung belanda dan lotion nanopartikel baik formula I,II ataupun III, dari minggu ke 1 sampai minggu ke 3 hasilnya homogen.

Hasil pengukuran $\mathrm{pH}$ terlihat bahwa lotion ekstrak terung belanda dan lotion nanopartikel ekstrak terong belanda memenuhi persyaratan SNI yaitu pH untuk sediaan topikal yaitu antara 4-8. Nilai $\mathrm{pH}$ sediaan dapat mempengaruhi stabilitas, kenyamanan, dan keamanan penggunaan sediaan pada kulit.

Hasil uji daya sebar lotion ekstrak terong belanda antara 5,0 sampai 6,5 . Pada pengujian daya sebar peel off nanopartikel terong belanda diameter yang di hasilkan lebih besar dibandingkan pada peel off ekstrak terong belanda dikarenakan bentuk nanopartikel memudahkan sediaan untuk menyebar lebih luas sehingga apabila sediaan ini digunakan akan menjangkau area yang lebih luas sehingga efeknya juga lebih optimal. Pengujian daya sebar bertujuan untuk melihat kemampuan penyebaran sediaan losio pada saat penggunaan di permukaan kulit. Lotion diharapkan mampu menyebar dan mudah saat diaplikasikan tanpa memerlukan tekanan yang berarti. Syarat daya sebar untuk sediaan topikal adalah 5-7 cm, yang menunjukkan konsistensi semisolid yang sangat nyaman dalam penggunaannya (Garg dkk., 2002). Pada umumnya sediaan dengan viskositas yang berbeda-beda, akan menghasilkan daya sebar yang berbeda pula, karena hambatan pada masing-masing sediaan untuk menyebar berbeda juga besarnya. Daya sebar yang baik menyebabkan kontak antara obat dengan kulit menjadi luas, sehingga absorpsi obat ke kulit berlangsung cepat.

Hasil uji viskositas pada ketiga formula lotion ekstrak terong belanda sekitar 3000-3900 cp, sehingga dapat dikatakan bahwa semua formula yang dikembangkan memenuhi persyaratan viskositas lotion menurut SNI yaitu 2000-50000 cp. Viskositas yang terlalu tinggi akan mengurangi tingkat kenyamanan penggunaan karena sulit mengalir, sehingga saat mengeluarkan sediaan dari kemasan juga menjadi sulit. Viskositas yang rendah juga tidak diharapkan, hal ini dikarenakan bila sediaan terlalu encer, maka sediaan akan menetes saat diaplikasikan pada kulit sehingga sediaan tidak tinggal seluruhnya pada permukaan kulit. Berdasarkan pertimbangan-pertimbangan tersebut, maka viskositas suatu sediaan harus 
optimum sesuai tujuan aplikasi (Martin dkk., 1993).

Hasil analisis aktivitas antioksidan lotion ekstrak terong belanda menunjukkan aktivitas antioksidan dengan nilai IC50 berturut-turut adalah $94 \pm 2,1 \mu \mathrm{g} / \mathrm{mL}$ dan $62 \pm 2,5 \mu \mathrm{g} / \mathrm{mL}$. Hasil ini menunjukkan bahwa dengan pembuatan nanopartikel maka daya antioksidannya menjadi lebih kecil atau daya efektivitas sebagai antioksidan menjadi lebih baik.

\section{Simpulan}

Lotion ekstrak terong belanda yang dihasilkan memenuhi syarat evaluasi fisik sediaan. Nilai IC50 lotion nanopartikel ekstrak terong belanda adalah $62 \mu \mathrm{g} / \mathrm{mL}$. Ukuran partikel dari ekstrak nanopartikel adalah 182,4 $\mu \mathrm{m}$. Lotion nanopartikel ekstrak terong belanda mempunyai kestabilan yang baik. Perlu dilakukan pembuatan bentuk sediaan yang lain dengan tujuan sebagai kosmetika.

\section{Ucapan Terimakasih}

Peneliti mengucapkan terima kasih kepada Lembaga Penelitian dan Pengabdian Masyarakat Universitas Muhammadiyah Pekajangan Pekalongan, Kepala Program Studi Sarjana Farmasi Fakultas Ilmu Kesehatan Universitas Muhammadiyah Pekajangan Pekalongan dan kepada seluruh Tim peneliti.

\section{Daftar Pustaka}

Abdassah, M., 2009, Nanopartikel dengan gelasi ionik, Farmaka, 15, 45-52.

Dewandari, K.T., Yuliani, S., and Yasni, 2013, Ekstraksi dan Karakterisasi Nanopartikel Ekstrak Sirih Merah (Piper Crocatum), J. Pascapanen, 10, 58-65.

Kurniasari, D. and Atun, S., 2017, Pembuatan Dan Karakterisasi Nanopartikel Ekstrak Etanol Temu Kunci (Boesenbergia pandurata) Pada Berbagai Variasi Komposisi Kitosan, J. Sains Dasar, 6, 31.

Martien, R., Adhyatmika, Irianto, I.D.K., Farida, V., and Sari, D.P., 2012, Perkembangan teknologi nanopartikel sebagai sistem penghantaran obat, Maj. Farm., 8, 133-144.

Susanti, N.M.P., Budiman, I.N.., and Warditiani, N.K., 2015, Skrining Fitokimia Ektrak Etanol 90 \% Daun
Katuk ( Sauropus androgynus ( L .) Merr .), Repos. Univ. Udayana, 83-86.

Wahyuni, S., Ariskn, A.M., Sabana Uli, C.M., Sahara Nur, W.S., Murtiningsih, T., and Putriningrum, R., 2013, Uji Manfaat Daun Kelor (Moringa aloifera Lamk) Untuk Mengobati Penyakit Hepatitis B, KesMaDaSka, 100-103.

SNI 16-4399-1996. Sediaan Tabir Surya. Jakarta: Badan Standardisasi Nasional. 